\title{
Exclusive contracts with private information in successive differentiated oligopolies
}

\author{
Barna Bakó*
}

February 12, 2013

\begin{abstract}
The purpose of this article is to analyze the incentives of manufacturers to deal exclusively with retailers in bilaterally duopolistic industries with brand differentiation by manufacturers. In contrast with the previous literature, exclusive contracts are shown to generate higher profits for manufacturers and retailers selling highly differentiated products, who thus have an incentive to insist on exclusive contracting. However, if the products are close substitutes no exclusivity will emerge in equilibrium. Furthermore, we show that exclusive contracts decrease both consumer and social welfare.
\end{abstract}

Keywords: exclusive contracts, product differentiation, vertical integration JEL Classification Codes: L20, L42, K20, D43, D83

\section{Introduction}

A puzzling feature of many industries is that manufacturers commit themselves to sell exclusively through few retailers to the final consumers. At first glance it can be hard to understand why producers would engage to lessen the downstream competition. Intuitively, one would expect that tougher competition leads to lower prices, which implies higher sales for the manufacturer. Yet, we encounter with such exclusive

*MTA-BCE "Lendület" Strategic Interactions Research Group, Corvinus University of Budapest, Department of Microeconomics, 1093, Budapest, Fővám tér 8, E225.a, Hungary, Tel./fax: +36 1 4825140, e-mail: barna.bako@uni-corvinus.hu 
contracts in several industries, with most notable examples in telecommunications, car industry and in the pharmaceutical industry. The practice of exclusive contracts has been a subject of interest in the recent literature, though most of the articles study such contracting situations suggesting triangle structures (monopolistic player on one side and duopolistic agents on the other side). While these results have generated important insights about the nature of such contracting games, it is fair to say that the analysis of exclusive contracts in bilaterally oligopolistic markets has been largely ignored in the literature and less is known about the consequences in set-ups where both the upstream and the downstream market contain more then one player.

Notable exceptions are Chang (1992), Dobson and Waterson (1996), Moner-Colonquea et al. (2004) and Mauleon et al. (2011). In his paper, Chang (1992) analyses the market equilibrium in a successive duopoly, where firms make decisions over exclusive dealing and output levels. He shows that the only equilibrium is that of a full exclusive dealing structure. Moreover, he claims that this outcome benefits the consumers by eliminating the marginalization problem. Dobson and Waterson (1996) generalize Chang (1992)'s analysis by allowing product and retailer's service differentiation. The authors claim that firms are better off with exclusive trading only when there is no or little differentiation between products and between services. On the other hand, with high levels of differentiation the equilibrium outcome involves non-exclusive contracts. Furthermore, Dobson and Waterson (1996) argue that a 'blanket ban' on exclusivity would be inappropriate since their results suggest that social welfare is higher with unrestricted competition when there is little differentiation. Moner-Colonquea et al. (2004) investigate the equilibrium distribution systems in a successive duopoly with manufacturers producing differentiated products with asymmetric demands. They show that manufacturers always distribute through both retailers whenever product differentiation is strong and brand asymmetry is moderate. However, if product differentiation and brand asymmetry are weak the equilibrium outcome is that manufacturers sell through a single retailer. They also show that when both product differentiation and brand asymmetry are strong an asymmetric equilibria arise, where one manufacturer sells exclusively through a retailer and the other manufacturer distributes through both retailers 11 Adopting a network theory perspective, Mauleon et al. (2011) analyze the endogenous formation of distribution systems between manufacturers of differentiated products and multi-product retailers. Both non-exclusive distribution and dealing networks and exclusive distribution

\footnotetext{
${ }^{1}$ Bakó (2012) gives an other explanation for the asymmetric equilibria, by analyzing the effects of exclusive contracts in vertically integrated oligopolies where manufacturers produce vertically differentiated products. His results suggest that firms prefer to deal exclusively with retailers. If the extent of consumers' heterogeneity is small, manufacturers offer exclusive contracts unilaterally and a mixed distribution system emerges. On the other hand, if consumers' valuation differ significantly all manufacturers engage in exclusive contracting.
} 
and dealing networks are found to be stable under a linear pricing contract. Similarly to the above mentioned articles, Mauleon et al. (2011) argue that under low-values of product differentiation the only pairwise stable network is the one characterized with non-exclusivity, but a high product differentiation can also lead to a network with exclusivity. Their welfare analysis suggests that restricting exclusive distribution and exclusive dealing arrangements might have a positive impact on social welfare as long as the degree of product differentiation is low.

Our results contradict these previous findings. Assuming contracts with private information, we show that the unique equilibrium outcome is the one with exclusive contracts by every manufacturer when products are highly-differentiated, while when products are close substitutes the equilibrium contains non-exclusivity. This is exactly the opposite what the cited literature suggests. In addition we show, that if manufacturers can deal secretly with retailers both consumer and social welfare is hurt when firms use exclusive contracts, no matter if the product differentiation is low or high.$^{2}$

It is well known ${ }^{3}$ that when retailers can observe the contracts offered by a manufacturer to different retailers the joint profit maximizing outcome can be achieved. This result, however, relies crucially on contract observability. If the manufacturer can deal secretly with the retailers a free-riding effect evolves that restrain the parties to achieve the joint profit of an integrated vertical structure. As first shown by Hart and Tirole (1990) in the presence of contract externalities exclusive contracts can be used to solve this problem (see also O'Brien and Shaffer (1992), McAfee and Schwartz || (1994) and Segal and Whinston (2003)) $\left.\right|^{4}$ They arrive to the conclusion that a single upstream producer, which sells its product through undifferentiated retailers always offers an exclusive contract to a retailer. Intuitively, in their case there is no loss from selling through a single retailer and contracting externalities are eliminated with exclusive representation. However, this result can be spurious if there is more than one producer. The reason is that while an exclusive contract solves the problem of opportunism between retailers, it pares down the manufacturer's sales, which, if it is unilateral, can lead to less profit for the producer. Such profit reducing effects

\footnotetext{
2 Mauleon et al. (2011) also consider contracts with two-part tariffs in which non-exclusive contracts emerge in equilibrium regardless of the value of product differentiation. However, this is not a unique equilibrium when product differentiation is strong, since in this case exclusive dealing and exclusive distribution also constitute an equilibrium. In this sense, their results are similar to our findings. Yet, they claim that if two-part tariffs are used, restricting non-exclusive distribution and non-exclusive dealing arrangements might have a positive effect on social welfare when product differentiation is weak. As we show, this is not the case if we introduce private informations.

${ }^{3}$ See Whinston $(2006)$ for discussions of these issues.

${ }^{4}$ The main concern of Hart and Tirole (1990) was vertical integration which was adopted to study exclusive contracts by O'Brien and Shaffer (1992).
} 
can outweigh the profit increasing effect arising by solving the problem of contracting externality. Therefore, the producers can experience a prisoners' dilemma in their contracting decision. As we will show in this paper this dilemma will emerge when products produced by manufacturers are sufficiently close substitutes. In this case the producers will abstain from using exclusive contracts.

\section{The model}

We consider the following vertical structure. There are two upstream manufacturers $\left(M_{1}\right.$ and $\left.M_{2}\right)$ and two downstream retailers $\left(R_{A}\right.$ and $\left.R_{B}\right)$. The manufacturers face constant marginal costs $c_{i},(i=1,2)$, the retailers, in addition to the costs of obtaining the products from the manufacturers have a constant unit cost $c_{j}(j=A, B)$, which are normalized to zero $\left(c_{A}=c_{B}=0\right)$. We assume that final goods are symmetrically differentiated, and the inverse demands for the final good $i$ can be given by

$$
p_{i}\left(q_{i}, q_{-i}\right)=1-q_{i}-\delta q_{-i}
$$

where $i,-i=1,2$, and $\delta \in(0,1)$. We interpret $\delta$ as the degree of product differentiation. For $\delta$ close to 1 downstream firms supply homogenous products, while for $\delta$ close to 0 the firms supply to independent markets.

The game $\Gamma$ we consider is as follows. First, manufacturers decide simultaneously whether or not to offer exclusive contracts to one of the retailers. This decision is observable for every player. Next, if a manufacturer decides not to engage in exclusive contracts, it will make secret offers to each retailer in the form of $\left(q_{i j}, t_{i j}\right)$, with $q_{i j}$ the quantity that the manufacturer $i$ offers to the retailer $j$, and $t_{i j}$ the total transfer that the manufacturer $i$ gets from retailer $j$. In the third step, retailers announce simultaneously whether they accept any of the offers. A retailer that rejects the offers has nothing to sell and earns zero profit. In the final stage quantity competition occurs among retailers, and markets clear.

Due to private contracts, when a retailer receives an offer it has to form a conjecture about the contracts received by the other retailer. Here, we restrict our attention to passive beliefs in which, a retailer after receiving an out of equilibrium offer, continues to believe that the other retailer receives its equilibrium offers (see Segal and Whinston (2003)). Furthermore, if a retailer receives an exclusive contract, then it knows the other retailer has not received any offer from the same manufacturer.

Let $\left(q_{1 A}^{*}, q_{1 B}^{*}, q_{2 A}^{*}, q_{2 B}^{*}, t_{1 A}^{*}, t_{1 B}^{*}, t_{2 A}^{*}, t_{2 B}^{*}\right)$ denote the equilibrium outcome. With passive beliefs if retailer $j(=A)$ receives an offer from manufacturer $i(=1)$ such that 
$\left(q_{1 A}, t_{1 A}\right) \neq\left(q_{1 A}^{*}, t_{1 A}^{*}\right)$ it still believes that the other retailer receives its equilibrium offers $\left(q_{i j}^{*}, t_{i j}^{*}\right)_{i j \neq 1 A}$ and accepts this contract if and only if $p_{1}\left(q_{1 A}+q_{1 B}^{*}, q_{2 A}^{*}+q_{2 B}^{*}\right) q_{1 A} \geq$ $t_{1 A}$ and $p_{2}\left(q_{2 A}^{*}+q_{2 B}^{*}, q_{1 A}+q_{1 B}^{*}\right) q_{2 A}^{*} \geq t_{2 A}^{*}$ respectively. Given this, the manufacturer's offer must be pairwise stable in the sense that

$$
q_{1 A}^{*}=\arg \max _{q_{1 A}}\left[\left(p_{1 A}-c_{1}\right) q_{1 A}+t_{1 B}^{*}-c_{1} q_{1 B}^{*}\right]
$$

which is the joint profit of $M_{1}$ and $R_{A}$. Moreover, these are the same conditions that would hold if the manufacturers wouldn't exist and the retailers would compete as multi-product duopolists, each with $c_{1}$ and $c_{2}$ product specific marginal costs.

We solve the game by backward induction. First consider the subgame where the manufacturers don't commit themselves to sell exclusively for any of the downstream players and offer a non-exclusive contract to both of the retailers. In equilibrium $\left(q_{1 A}^{*}, q_{1 B}^{*}, q_{2 A}^{*}, q_{2 B}^{*}\right)$ must satisfy

$$
\begin{aligned}
& q_{1 A}^{*}=\arg \max _{q_{1 A}}\left[p_{1}\left(q_{1 A}+q_{1 B}^{*}, q_{2 A}^{*}+q_{2 B}^{*}\right)-c_{1}\right] q_{1 A} \\
& q_{1 B}^{*}=\arg \max _{q_{1 B}}\left[p_{1}\left(q_{1 A}^{*}+q_{1 B}, q_{2 A}^{*}+q_{2 B}^{*}\right)-c_{1}\right] q_{1 B} \\
& q_{2 A}^{*}=\arg \max _{q_{2 A}}\left[p_{2}\left(q_{2 A}+q_{2 B}^{*}, q_{1 A}^{*}+q_{1 B}^{*}\right)-c_{2}\right] q_{2 A} \\
& q_{2 B}^{*}=\arg \max _{q_{2 B}}\left[p_{2}\left(q_{2 A}^{*}+q_{2 B}, q_{1 A}^{*}+q_{1 B}^{*}\right)-c_{2}\right] q_{2 B}
\end{aligned}
$$

which yields

$$
q_{i j}^{*}=\frac{3\left(1-c_{i}\right)-2 \delta\left(1-c_{-i}\right)}{9-4 \delta^{2}}
$$

where $i,-i=1,2 ; i \neq-i$ and $j=A, B$. Equilibrium profits and prices thus equal

$$
\begin{gathered}
\pi_{i}^{*}=\frac{2\left[3\left(1-c_{i}\right)-2 \delta\left(1-c_{-i}\right)\right]^{2}}{\left(9-4 \delta^{2}\right)^{2}} \\
p_{i}^{*}=\frac{3\left(1+2 c_{i}\right)-2 \delta\left(1-c_{-i}\right)-4 \delta^{2} c_{i}}{9-4 \delta^{2}}
\end{gathered}
$$

where $i,-i=1,2$ and $i \neq-i$.

Now consider the case when $M_{1}$ offers an exclusive contract to a retailer, say $R_{A}$. In this case the product of $M_{1}$ is available for purchasing only at $R_{A}$, yet the other 
manufacturer's product is still available for sale at any retailer. In this case the problem (3) boils down to

$$
\begin{aligned}
& q_{1 A}^{*}=\arg \max _{q_{1 A}}\left[p_{1}\left(q_{1 A}+0, q_{2 A}^{*}+q_{2 B}^{*}\right)-c_{1}\right] q_{1 A} \\
& q_{2 A}^{*}=\arg \max _{q_{2 A}}\left[p_{2}\left(q_{2 A}+q_{2 B}^{*}, q_{1 A}^{*}+0\right)-c_{2}\right] q_{2 A} \\
& q_{2 B}^{*}=\arg \max _{q_{2 B}}\left[p_{2}\left(q_{2 A}^{*}+q_{2 B}, q_{1 A}^{*}+0\right)-c_{2}\right] q_{2 B}
\end{aligned}
$$

Solving for $q_{1 A}, q_{2 A}$ and $q_{2 B}$ yields

$$
\begin{gathered}
\pi_{1}^{*}=\frac{\left[3\left(1-c_{1}\right)-2 \delta\left(1-c_{2}\right)\right]^{2}}{4\left(3-\delta^{2}\right)^{2}} \\
\pi_{2}^{*}=\frac{\left[2\left(1-c_{2}\right)-\delta\left(1-c_{1}\right)\right]^{2}}{2\left(3-\delta^{2}\right)^{2}}
\end{gathered}
$$

and

$$
\begin{aligned}
& p_{1}^{*}=\frac{3\left(1+c_{1}\right)-2 \delta\left(1-c_{2}\right)+2 \delta^{2}\left(c_{1}\right)}{2\left(3-\delta^{2}\right)} \\
& p_{2}^{*}=\frac{2\left(1+2 c_{2}\right)-\delta\left(1-c_{1}\right)-2 \delta^{2}\left(c_{2}\right)}{2\left(3-\delta^{2}\right)}
\end{aligned}
$$

Then, by solving the game backward, we obtain the manufacturers' payoffs in the different sub-games at stage 1 as shown in Table 1.

Table 1: The payoff matrix

\begin{tabular}{crccc}
\hline \hline & & & $M_{2}$ & \\
& & & & \\
& & & & \\
\multirow{3}{*}{$M_{1}$} & no contract & $\left(a_{1}, a_{2}\right)$ & $\left(e_{1}, b_{2}\right)$ & $\left(e_{1}, b_{2}\right)$ \\
& $R_{A}$ & $\left(b_{1}, e_{2}\right)$ & $\left(d_{1}, d_{2}\right)$ & $\left(d_{1}, d_{2}\right)$ \\
& $R_{B}$ & $\left(b_{1}, e_{2}\right)$ & $\left(d_{1}, d_{2}\right)$ & $\left(d_{1}, d_{2}\right)$ \\
\hline
\end{tabular}

where $i,-i=1,2$ and

$\begin{aligned} a_{i}=\frac{2\left[3\left(1-c_{i}\right)-2 \delta\left(1-c_{-i}\right)\right]^{2}}{\left(9-4 \delta^{2}\right)^{2}} & b_{i}=\frac{\left[3\left(1-c_{i}\right)-2 \delta\left(1-c_{-i}\right)\right]^{2}}{4\left(3-\delta^{2}\right)^{2}} \\ & {\left[2\left(1-c_{i}\right)-\delta\left(1-c_{-i}\right)\right]^{2} }\end{aligned}$

$e_{i}=\frac{\left[2\left(1-c_{i}\right)-\delta\left(1-c_{-i}\right)\right]^{2}}{2\left(3-\delta^{2}\right)^{2}} \quad d_{i}=\frac{\left[2\left(1-c_{i}\right)-\delta\left(1-c_{-i}\right)\right]^{2}}{\left(4-\delta^{2}\right)^{2}}$ 
The game has several equilibria depending on the level of product differentiation. One can easily see that if $\delta \in(\sqrt{2-\sqrt{2}}, 1)$ the unique subgame perfect equilibria is when the manufacturers don't engage in exclusive contracting and both of them offer a contract to the retailers with strictly positive quantities such that condition $(3)$ is satisfied. On the other hand, if the products are highly differentiated, i.e. $\delta \in\left(0, \frac{\sqrt{3(2-\sqrt{2})}}{2}\right)$, both manufacturers will offer an exclusive contract to a retailer. Under intermediate differentiation levels, that is when $\delta \in\left(\frac{\sqrt{3(2-\sqrt{2})}}{2}, \sqrt{2-\sqrt{2}}\right)$, both outcomes can emerge in equilibrium. Note that there is no equilibrium in which only one of the manufacturer would offer an exclusive contract to a retailer. This can occur only under mixed strategies.

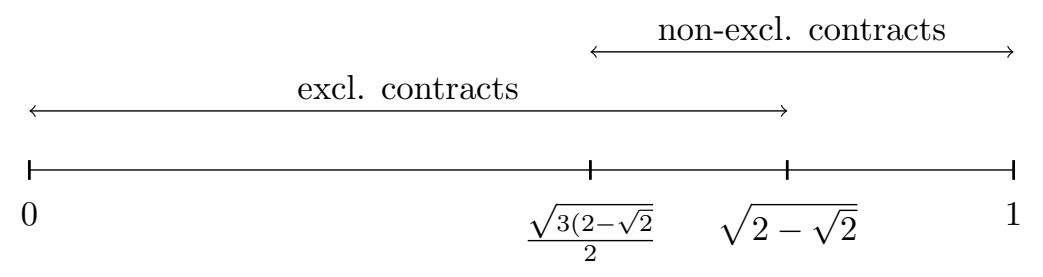

Figure 1: Equilibrium outcomes.

The following proposition characterizes the equilibrium of the contracting game.

Proposition 2.1 Under highly differentiated products manufacturers engage in exclusive contracting, while when the products are less differentiated the manufacturers will offer non-exclusive contracts to the retailers.

The intuition for the results captured in Proposition 2.1 is straightforward. For $\delta$ belonging to the interval $\left(0, \frac{\sqrt{3(2-\sqrt{2})}}{2}\right)$ the product differentiation is too strong and producers use exclusive contracts to solve the problem of contracting externality. If both manufacturers happen to sign an exclusive contract with the same retailer, the other retailer is driven out from the market, however this is not an explicit purpose for manufacturers. On the other hand, if the products are close substitutes producers are experiencing a prisoners' dilemma. Exclusive contracts still could solve the problem caused by contract externalities, but by using unilateral exclusive contract a 
manufacturer restricts its output, which primarily benefits the other firm. The firm without exclusivity gains from the restriction of output by the other firm, without having to restrict output himself. The manufacturer with an exclusive contracts commits himself to be less aggressive, which ultimately has a negative effect on his profit. Therefore, in equilibrium both manufacturers will choose to sell without exclusive contracts.

\section{Welfare implications}

This section discusses the welfare implications of our model. To evaluate consumer welfare we consider a representative consumer's utility function which is consistent with the demand system given by (1). Such a utility in monetary units of consuming $q_{i}$ units of product $i$, and $q_{j}$ units of product $j$, can be given as

$$
U\left(q_{i}, q_{-i}\right)=q_{i}+q_{-i}-\frac{1}{2}\left(q_{i}^{2}+2 \delta q_{i} q_{-i}+q_{-i}^{2}\right)
$$

Plugging into this the equilibrium quantities and subtracting the costs involved by consuming these quantities, we get the consumer surpluses for the different subcases. Denote by $C W^{n c}$ the consumer welfare that would prevail in the case when manufacturers don't sign exclusive contracts, and by $C W^{1 k 2 l}(k, l=A, B)$ when both manufacturers sign an exclusive contracts. It can be shown that

Proposition 3.1

$$
C W^{n c}>C W^{1 k 2 l} \quad k, l=A, B
$$

always holds.

Thus, a social planner who is more concerned about the consumer welfare than the total surplus, should ban the practice of exclusive contracts. To evaluate the welfare effects, we compare the situations with exclusive contracts to the situation in which exclusivity is not possible. Social welfare is given by

$$
W=C W+\pi_{1}+\pi_{2}
$$

where $\pi_{i}$ represents the joint profits of manufacturer $i$ and his downstream retailer(s). Using the consumers' welfare and equilibrium profit levels given in Section 1, yields the following $(k, l=A, B)$

$$
W^{n c}>W^{1 k 2 l} \quad \text { for } \quad \delta \in(0, \sqrt{2-\sqrt{2}})
$$


We already know that in the case when manufacturers produce highly differentiated products they would engage in exclusive dealing in their practice of selling their products. The outcome emerging in equilibrium always leads to a smaller aggregate surplus, compared to the case where using exclusive contracts is not possible. Moreover, if the products are close substitutes the profits gain by manufacturers exceeds the loss of consumer welfare caused by exclusive contracts. However in this case the outcome with exclusives will not emerge in the equilibrium. This is summarized in the following proposition.

Proposition 3.2 Social welfare in the case in which manufacturers sell with nonexclusive contracts exceeds social welfare in the case in which manufacturers sell their products exclusively if the products produced by the manufacturers are highly differentiated.

\section{Conclusion}

In the prevailing literature on exclusive contracts it has been argued that manufacturers will engage in using exclusive contracts when products are undifferentiated, and will never sign such contracts, if the products are highly differentiated. This result, however, depends crucially on the fact that the upstream market is supposed to be monopolistic. The results change if we consider multiplayer upstream market. As we have shown in this paper, the manufacturers will engage in exclusive contracting when the product differentiation is strong. In this case an exclusivity will solve the problem of contract externality. If the products are less differentiated the manufacturers experience a prisoner's dilemma, where, by having an incentive to solve the externality problem, a unilateral switch leads to a lower profit. In this case manufacturers will offer non-exclusivity to the retailers. The outcome with no exclusive dealing is shown to generate higher consumer welfare, as well as higher aggregate surplus.

\section{References}

d'Aspremont, C., Gabszewicz, J. and Thisse, J (1979), "On Hotelling's Stability in Competition", Econometrica, 1145-1151.

Bakó, B. (2012), "Exclusive contracts with vertically differenciated products", Economics BUlletin, 1312-1319. 
O'Brien, D. P. and Shaffer, G. (1992). "Vertical Control with Bilateral Contracts", RAND Journal of Economies, 299-308.

Chang, M. H. (1992), "Exclusive Dealing Contracts in a Successive Duopoly with Side Payments", Southern Economic Journal,180-193.

Dobson, P. W. and Waterson, M. (1996), "Exclusive Trading Contracts in Successive Differentiated Duopoly", Southern Economic Journal, 361-377.

Hart, O. and Tirole, J. (1990), "Vertical Integration And Market Foreclosure", Brookings Papers on Economic Activity, 205-276.

Mauleon, A., Sempere-Monerris, J. J. and Vannetelbosch, V. J. (2011), "Networks of manufacturers and retailers", Journal of Economic Behavior and Organization, 351-367.

McAfee, R. P. and Schwartz, M. (1994), "Opportunism in vertical contracting: Nondiscrimination, exclusivity, and uniformity", American Economic Review, 210230 .

Moner-Colonques, R., Sempero-Monerris, J. J. and Urbano, A. (2004), "The Manufacturers' Choice of Distribution Policy under Successive Duopoly", Southern Economic Journal, 532-548.

Salant, S., Switzer, S. and Reynolds, R. (1983), "Losses from Horizontal Merger: The Effects of an Exogenous Change in Industry Structure on Cournot-Nash Equilibrium", Quarterly Journal of Economics, 185-199.

Segal, I. and Whinston, M. D. (2003), "Robust predictions for bilateral contracting with externalities", Econometrica, 757-791.

Whinston, M. D. (2006), Lectures on Antitrust Economics, MIT Press, Cambridge, Massachusetts. 